\title{
Tuning Vibrational Strong Coupling with Co-Resonators
}

Iffat Imran, Giulia E. Nicolai, Nicholas D. Stavinski, and Justin R. Sparks*

Department of Chemistry, Muhlenberg College, Allentown, Pennsylvania 18104, United States

*jsparks@muhlenberg.edu

\section{Supplementary Information}

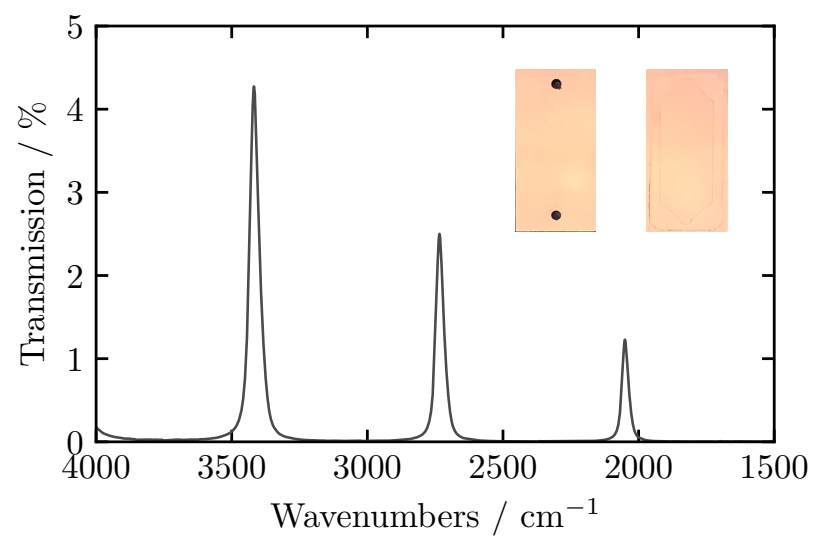

Figure S1: Representative spectrum of the empty (air) Fabry-Pérot optical cavity shown in Figure 1a. The inset shows the $\mathrm{CaF}_{2}$ windows with the spacer fabricated via photolithography. 

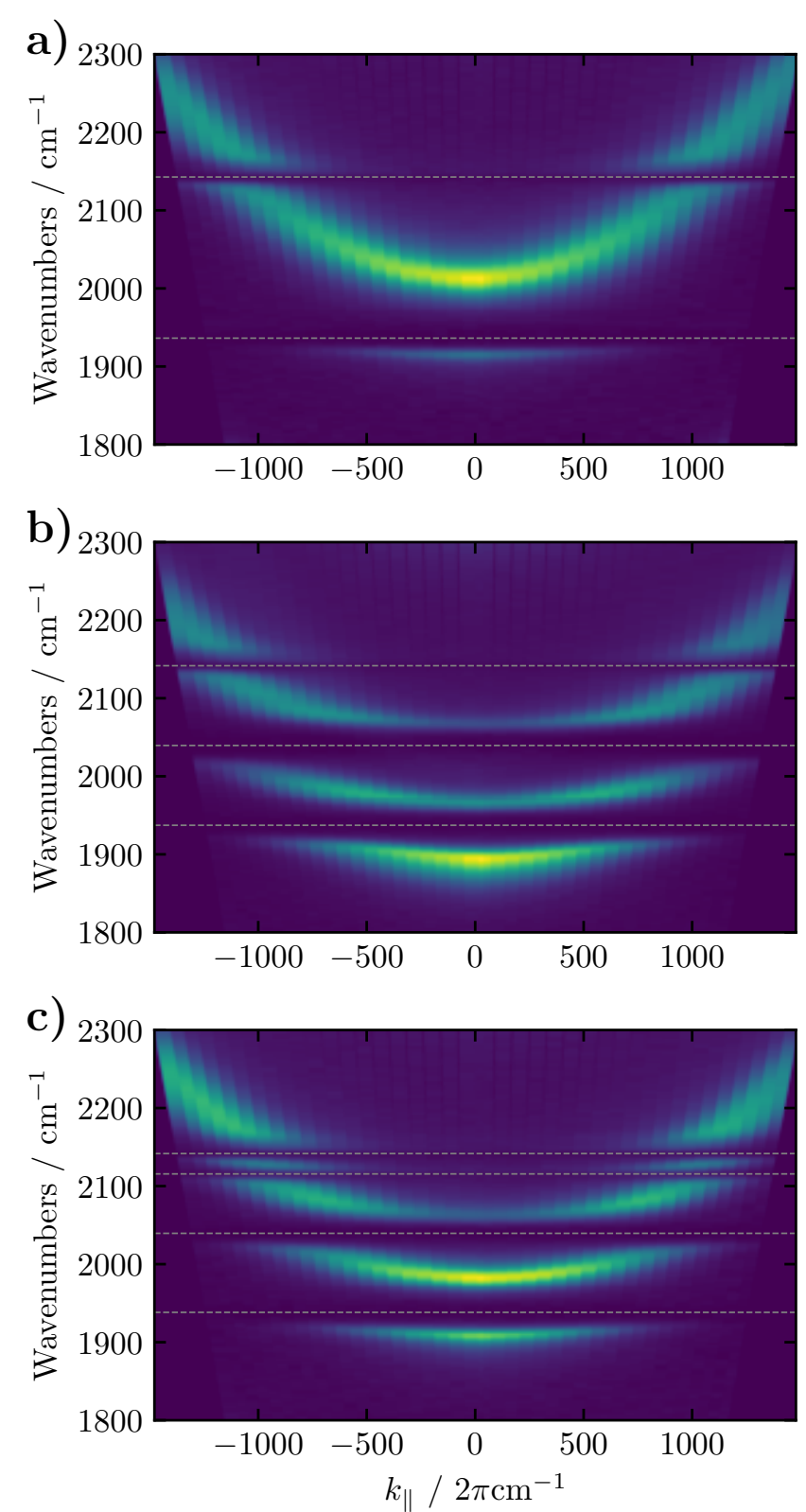

Figure S2: Experimental $k_{\|}$dispersion of the polariton branches for the same datasets in (a) Figure $2 \mathrm{~b}$ (three polaritons), (b) Figure 3b (four polaritons), and (c) Figure 5b (five polaritons). 


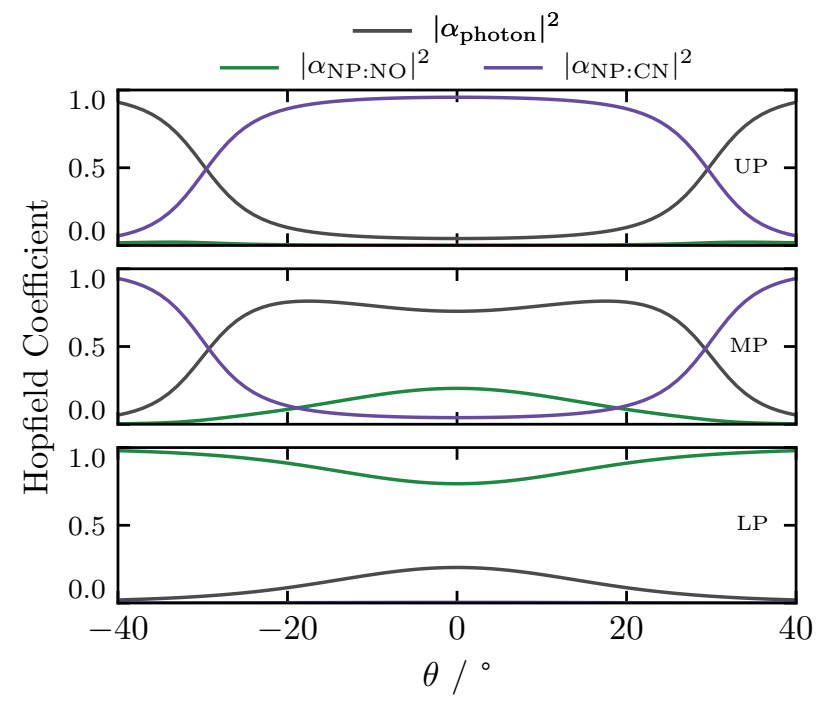

Figure S3: Hopfield coefficients as a function of angle for the $0.9 \mathrm{M} \mathrm{Fe}(\mathrm{CN})_{5} \mathrm{NO}^{2-}$ solution. 

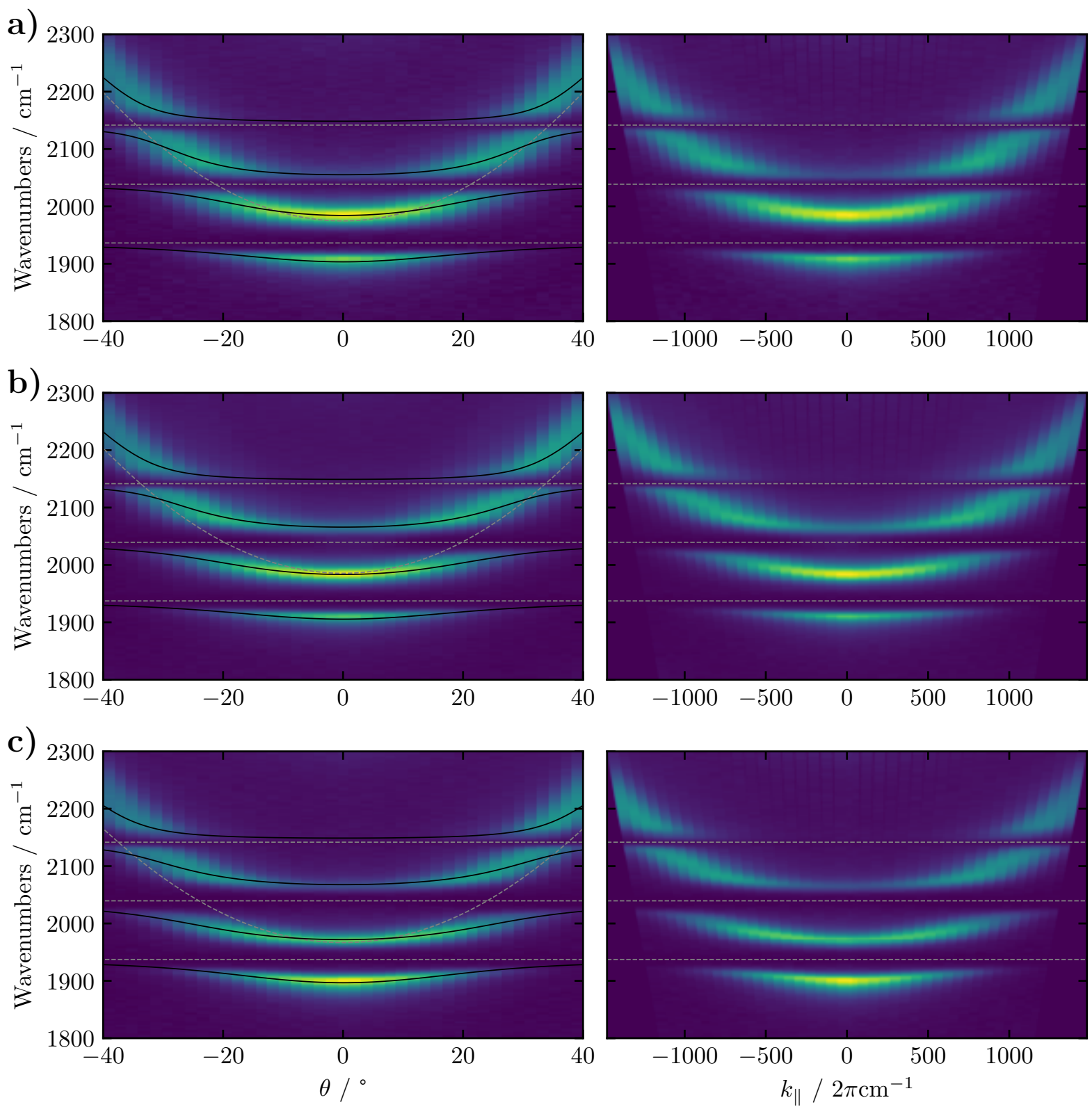

Figure S4: Experimental angular (left) and $k_{\|}$(right) dispersion of the polariton branches (colormap) along with uncoupled molecular and optical resonances for reference as horizontal and curved dashed lines, respectively, for solutions of $0.9 \mathrm{M} \mathrm{Fe}(\mathrm{CN})_{5} \mathrm{NO}^{2-}$ with (a) $0.15 \mathrm{M}$, (b) $0.30 \mathrm{M}$, and (c) $0.45 \mathrm{M}$ $\mathrm{Fe}(\mathrm{CN})_{6}{ }^{4-}$. The results of fitting Equation 3 are overlaid as solid lines. 
a)

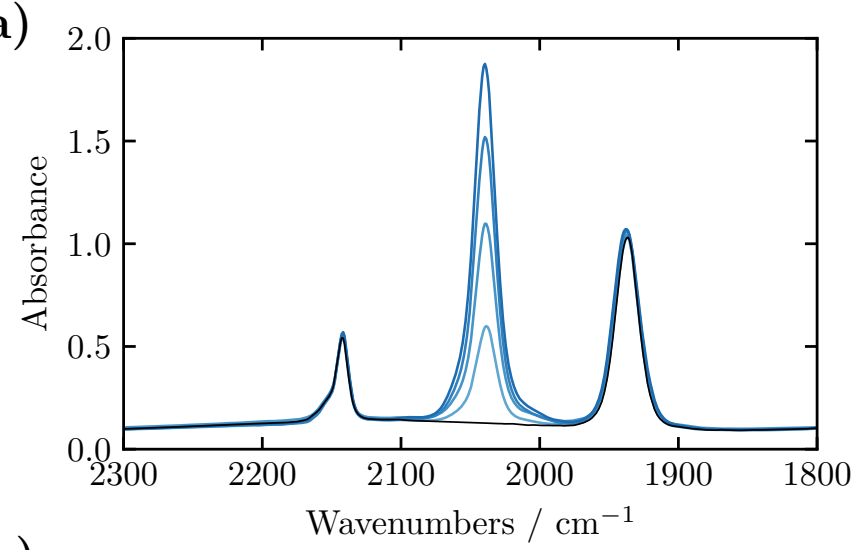

b)

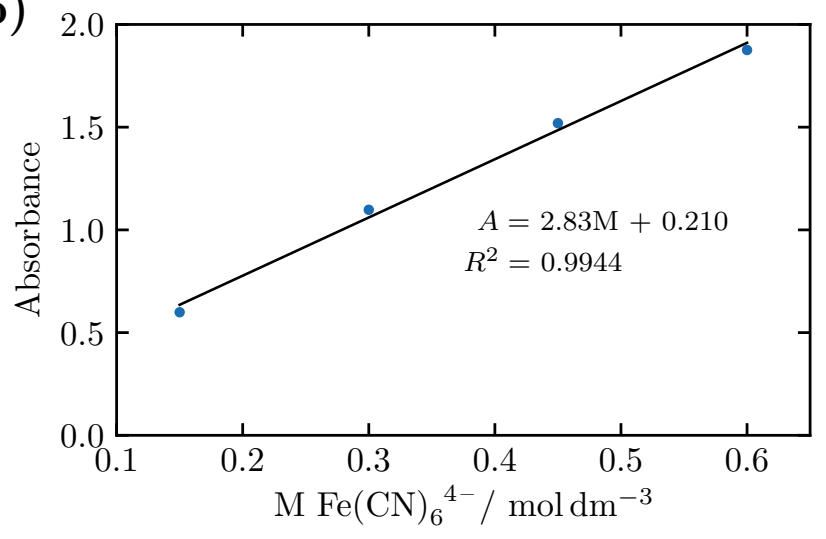

c)

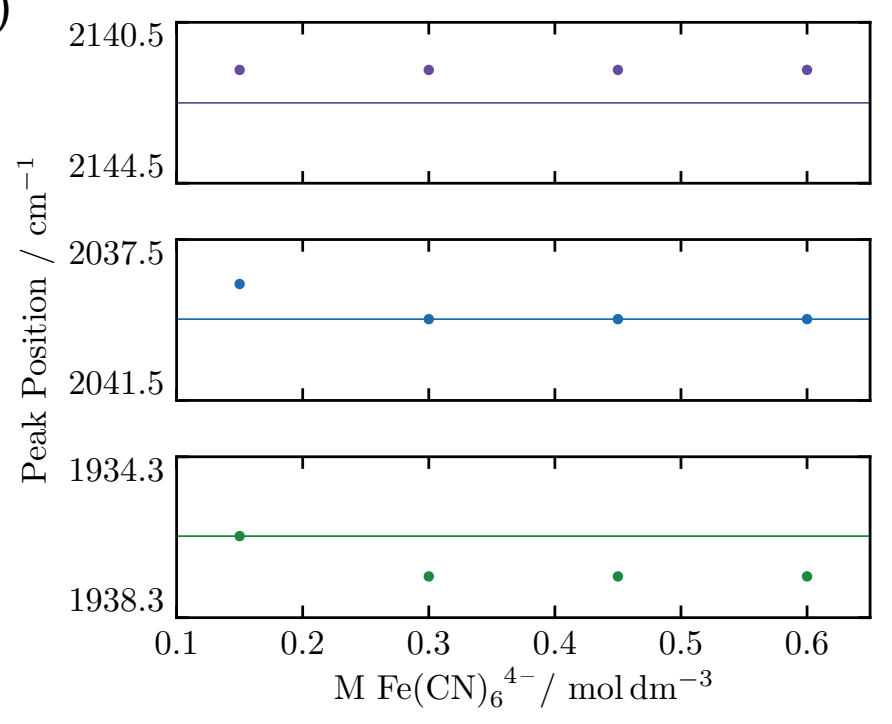

d)

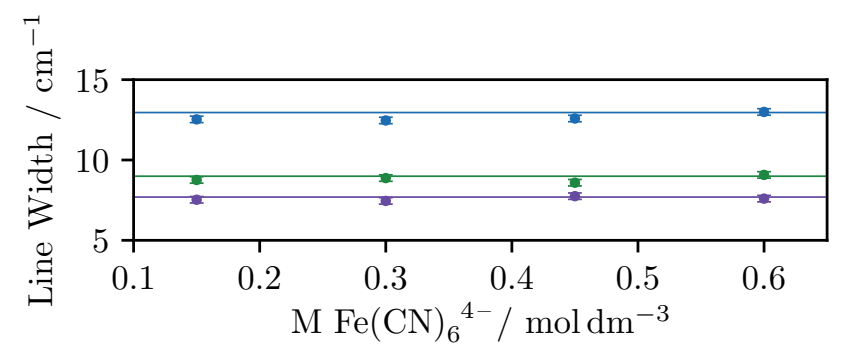

Figure S5: (a) Calculated (see Methods) transmission spectra of solutions in a 7.2 um cavity without gold mirrors as the concentration of $\mathrm{Fe}(\mathrm{CN})_{6}{ }^{4-}$ changes from $0.15 \mathrm{M}$ to $0.60 \mathrm{M}$ while keeping the concentration of $\mathrm{Fe}(\mathrm{CN})_{5} \mathrm{NO}^{2-}$ constant at $0.9 \mathrm{M}$. The black spectrum is the $0.9 \mathrm{M} \mathrm{Fe}(\mathrm{CN})_{5} \mathrm{NO}^{2-}$ solution for reference. (b) The absorbance of the $\mathrm{Fe}^{\mathrm{II}}$ :CN resonance increases linearly over this concentration range with a baseline absorbance due to reflection from the window surfaces. The (c) peak positions and (d) line widths of the NP:CN, Fe ${ }^{\mathrm{II}}: \mathrm{CN}$, and NP:NO resonances do not change significantly as the $\mathrm{Fe}(\mathrm{CN})_{6}{ }^{4-}$ concentration increases. The widths of the wavenumber axes in (c) represent the error range of the interaction potential fits. Both (c) and (d) use the color coding from Figure 1. 


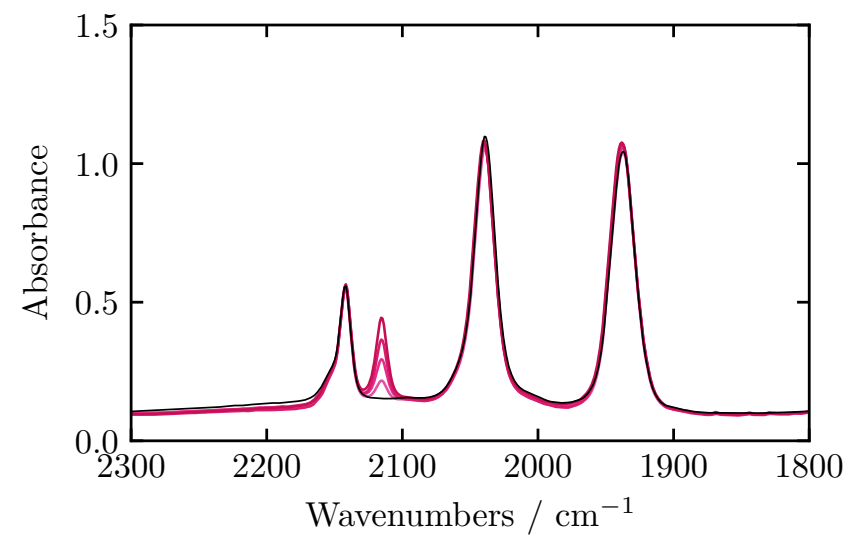

Figure S6: Calculated (see Methods) transmission spectra of solutions in a $7.2 \mu \mathrm{m}$ cavity without gold mirrors as the concentration of $\mathrm{Fe}(\mathrm{CN})_{6}{ }^{3-}$ changes from $0.10 \mathrm{M}$ to $0.40 \mathrm{M}$ while keeping the concentrations of $\mathrm{Fe}(\mathrm{CN})_{5} \mathrm{NO}^{2-}$ and $\mathrm{Fe}(\mathrm{CN})_{6}{ }^{4-}$ constant at $0.9 \mathrm{M}$ and $0.3 \mathrm{M}$, respectively. The black spectrum is the $0.9 \mathrm{M} \mathrm{Fe}(\mathrm{CN})_{5} \mathrm{NO}^{2-}$ and $0.3 \mathrm{M} \mathrm{Fe}(\mathrm{CN})_{6}{ }^{4-}$ solution for reference. 